\title{
How Will the Technological Shift in Transportation Impact Cities? A Review of Quantitative Studies on the Impacts of New Transportation Technologies
}

\author{
Tanvi Maheshwari ${ }^{1, *(D)}$ and Kay W. Axhausen ${ }^{2}$ \\ 1 Future Cities Laboratory Singapore, Singapore-ETH Centre, Singapore 138602, Singapore \\ 2 Institute for Transport Planning and Systems, ETH Zürich, 8093 Zürich, Switzerland; \\ axhausen@ivt.baug.ethz.ch \\ * Correspondence: maheshwari@arch.ethz.ch; Tel.: +65-6601-6076
}

\section{check for} updates

Citation: Maheshwari, T.; Axhausen, K.W. How Will the Technological Shift in Transportation Impact Cities? A Review of Quantitative Studies on the Impacts of New Transportation Technologies. Sustainability 2021, 13, 3013. https://doi.org/10.3390/ su13063013

\section{Academic Editors}

Mahyar Amirgholy and

Mehdi Nourinejad

Received: 28 January 2021

Accepted: 8 March 2021

Published: 10 March 2021

Publisher's Note: MDPI stays neutral with regard to jurisdictional claims in published maps and institutional affiliations.

Copyright: (c) 2021 by the authors. Licensee MDPI, Basel, Switzerland. This article is an open access article distributed under the terms and conditions of the Creative Commons Attribution (CC BY) license (https:// creativecommons.org/licenses/by/ $4.0 /)$.

\begin{abstract}
Recent developments in vehicle automation, connectivity, electro-mobility and ridesharing are expected to transform urban mobility patterns and reshape cities. There is enormous uncertainty about how these technological developments, collectively referred to as the 'technological shift in transportation', may impact cities. This paper examines whether the technological shift in transportation will lead cities on a path to sustainability in five aspects-traffic flow, space use, energy consumption, transit and active mobility and economic affordability - through a review of 34 quantitative studies. We find that these studies backed by analytical and simulation models can provide more precise answers, and their results tend to contradict each other based on starting conditions, modelling methods and other driving factors. These driving factors fall within four categories: technological integration, policy, operations and urban planning. The interaction of these driving forces will determine if the technological shift improves transportation sustainability or is detrimental for the city in the long term.
\end{abstract}

Keywords: autonomous vehicles; connected vehicles; shared vehicles; simulation modelling; urban planning; policy

\section{Introduction}

The urban transportation sector has witnessed several technological innovations in the last two decades, notable among these being the accelerated pace of development in vehicle automation technologies [1,2]. There is no clear consensus on when automated vehicles (AVs) would be widely deployed, and to what level of automation [3,4], with implementation horizons constantly shifting. At the same time there are emerging systems and technologies in transportation, which in combination with automation, have the potential to fundamentally shift existing mobility patterns, ushering in a 'new mobility era' [5]. Platform-based ride-hailing systems, developments in affordable electric vehicles with constant improvements in batteries [6,7] and growing connectivity and sensing in our environment, marked by latest developments in $5 G$ technology [8,9], are examples of such innovations. These technologies have been variously described as a series of isolated technological disruptions $[10,11]$, that amount to a revolution when seen as a whole $[6,12,13]$. In this paper, we refer to the combination of vehicle automation and other enabling technologies as the 'technological shift in transportation'.

It is as yet uncertain how the technological shift will impact cities. Those that claim that these technologies harbinger the next big paradigm shift in transportation often cite their environmental, safety, speed, space and cost-saving benefits. But many critics find such claims highly exaggerated given the current state of technology and uncertainty regarding their impacts. Even if the latter view prevails, AVs and other supporting technologies have already garnered significant interest in research, planning agencies and private compa- 
nies. A more nuanced understanding of the purported benefits and dangers can benefit this discussion.

This review investigates how the technological shift in transportation will impact cities, whether it will set them on the path to sustainability or be detrimental to it. There is much debate about how one defines 'sustainability' and 'sustainable development', but a widely accepted view is to carefully balance environmental concerns with economic growth [14]. Richardson developed a framework to analyze 'sustainable transport' based on a literature review, and found 'societal factors', safety, access, fuel consumption, congestion and land use to be the key areas of concern [15,16]. Yigitcanlar and Dur's sustainability assessment model considers transit usage, walkability and bike-ability, and reduction in vehicle kilometers travelled as the key indicators for transport sustainability [17]. Similar indicators are also found in comprehensive documents such as the Sustainable Urban Development Goals published by the UN [18] and the EU's Urban Agenda [19]. This paper examines the impact of the technological shift on cities from five lenses of sustainabilityimpact on traffic flow and travel time, space consumption of transportation infrastructure, traffic-based emissions, transit and active mobility and cost of travel.

According to Papa and Ferreira [20], studies on the impacts of automated vehicles on cities can be classified in two types, studies on holistic scenarios and isolated impacts. The first type analyzes broader implications of the technological shift using qualitative or scenario-based approaches. Some examples of such type of studies include Chen et al.'s expert interview and surveys [21] and Stead and Vaddadi's review of scenario-based studies on the impact of AVs [22]. The second type of studies focusses on outcomes of the technological shift in limited areas, for example only emissions or congestion, using analytical approaches and simulation models, which is the focus of this paper.

\section{Studies on Isolated Impacts}

Building an accurate model of a complex system like a city and making accurate predictions regarding the impacts of a technology in nascent stages is difficult. Although the studies on isolated impacts of the technological shift are quantitatively modelled, they can hardly be considered accurate predictive models. Only a limited set of parameters can be considered in hypothetical models and the choice of these parameters is highly subjective, which leads to diverging results. However, qualitative holistic scenario-based studies face similar challenges of over-simplification of reality and diverse interpretations [22]. Despite the similar challenges in both quantitative and qualitative approaches to future thinking, often, quantitative analyses form the bulk of such studies and by virtue of being more precise, tangible and measurable, tend to be misconstrued as being more accurate. A better understanding of the underlying assumptions, and the selected parameters that lead to the diverging results, can not only help us navigate the complex inter-relationship between planning and policy decisions and impact on transport sustainability, but also expose the precariousness of quantitative models used to study futuristic technologies such as AVs.

Thirty-four peer-reviewed articles published between 2011 and 2020 were selected for this review (see Appendix A for a complete list and description of selection criteria). All studies use modelling and simulation as the primary method of analysis. Automated vehicles (AV) are considered in all studies, and half the studies analyze the impacts of shared automated vehicle (SAV), with some degree of connectedness. Four studies specifically look at the impacts of connected automated vehicles (CAV), and three studies also include shared electric AVs (SEAV). Eleven of the simulations are modelled in a hypothetical environment with no corresponding real location. The rest are located in diverse geographies in the US, Europe and Asia. Please note that the term 'vehicle' here only includes passenger commute vehicles, ranging in size from a small four-seater to a bus, and serving different purposes, from a private car, to a taxi, shuttle, or bus, as detailed in Appendix A. We will now examine how the technological shift in transportation will impact cities in five areas. 


\subsection{Will the Shift Augment or Curtail Traffic Flow?}

Studies on the impact of the technological shift on traffic flow present two opposing points of view. The first viewpoint suggests that there will be significant improvements in traffic flow as the technological shift enables more efficient driving and intelligent management of modes. In another view, these gains may be cancelled out by additional travel due to induced demand, latent demand, change in the value of travel time and increased detours/empty mileage.

According to some studies, AVs drive more efficiently at higher speeds through smoother driving and a shorter minimum headway, resulting in an increase in capacity. Wagner [23] demonstrates through traffic simulation studies that autonomous systems reduce intersection delays by $5-80 \%$. Zhai et al. study the impact of replacing one bus line with an automated bus on-demand system in Fuyang prefecture in China, and find the system overwhelmingly advantageous, with less road resource occupation, shorter passenger waiting times and more efficient utilization of vehicle capacity [24]. However, a microscopic traffic simulation by Arnaout and Arnaout [25] suggests that capacity gains are not significant under a low to moderate penetration rate of AVs. For noticeable gains in traffic flow, at least $40 \%$ of all vehicles on the street need to be automated. Xie et al. [26] find that traffic efficiency can be improved when autonomous vehicles drive more opportunistically in normal urban traffic scenarios, but this can also lead to more potential conflicts between the vehicles, leading to adverse safety impacts. Additionally, if the AV has to deliver similar rider comfort as today, it needs to accelerate and decelerate considerably slower than conventional vehicles, which can even reduce traffic flow from current levels [27].

The throughput of traffic at intersections can be dramatically improved with connected AVs (CAV). Friedrich [28] finds that with 100\% automated traffic, the capacity would increase to about 1120 cars/h per lane, a 40\% increase, due to better reaction time. Tachet et al. [29] replace traditional traffic lights with 'slot-based intersections' (SI) in a microscopic traffic simulation, and show that such a transition theoretically has the potential to double capacity at an intersection and significantly reduce delays. However, these SI simulations have been criticized for ignoring pedestrian and cyclist flow at the intersections [30].

Shared AVs (SAV) may further reduce the transport impact since fewer vehicles are required on the street to serve the same number of trips. For example, according to a simulation study, a fleet of 9000 vehicles can serve all taxi trips in Manhattan with an average waiting time of less than a minute [31]. If up to 10 minutes wait time is permitted, the fleet size can be as low as 6470 vehicles, according to agent-based simulations by Bauer et al. [32] for shared electric AV (SEAV) taxis in Manhattan, despite taking into account the extra time required for vehicle charging. Several other studies find a similar reduction in overall fleet size for SAVs in different operational contexts [33-36], but the magnitude of the reduction is subject to various external planning and operational policy decisions.

With reduced congestion on the street, the average total service time for shared vehicles may improve, even if we factor in the detour, waiting, pick-up and drop-off time, as demonstrated by an agent-based simulation study of SAV deployment in Austin, Texas [35]. Agent-based simulations of SAVs in Greenwich, UK, find a travel time reduction of up to $41 \%$ [37], and that in the Zurich area finds a substantial improvement in network performance (up to double the speed) [38]. However, the maximum speeds remain higher for private vehicles compared to pooled vehicles in the Zurich study, and contrary to the Austin study, Alonso-Mora et al. [33] observe greater delays due to detour, waiting times and Vehicle Kilometers Travelled (VKT) in their study for New York. The overall impact of vehicle sharing on traffic flow remains uncertain and depends on the size and capacity of the SAV fleet.

An interesting effect of vehicle automation is the change in the value of in-vehicle travel time, defined as the willingness-to-pay for a reduction of time spent in the vehicles. Vehicle automation will allow the user to spend a large portion of in-vehicle time 
productively engaged in other activities [39]. In a more radical vision of the future with automated vehicles, "time slots that were previously almost exclusively occupied by travel will dissolve into permeable channels of flows, permitting overlapping continuity of activities" [40]. On the other hand, reduced (perceived) travel time, and change in the value of travel time, may create new induced demand.

According to an activity-based model of Seattle, speed and capacity increases may improve regional mobility, but could also induce additional demand leading to more VKT [41]. A study of SAV implementation in Switzerland finds that the additional demand generated outweighs the capacity benefits or automation, and would lead to substantial increases in travel times [42]. Newly mobile population enabled by automation, such as children, elderly and the disabled, constitute a latent demand which may add to this induced demand. A mathematical modelling study estimates that increased travel under this effect could reach up to $40 \%$ [43]. The magnitude of induced and latent demand can only be very crudely speculated on at the moment, and will depend on attractiveness of AVs, SAVs, EVs, transit or active mobility, which are in turn influenced by urban planning and operational policy.

It is clear that the technological shift can both improve or deteriorate current traffic flows depending on various external driving factors and starting conditions. These are summarized in Appendix B Figure A1.

\subsection{Will the Shift Increase or Decrease the Spatial Imprint of Transportation?}

Transportation infrastructure such as roads and parking occupy a significant percentage of urban land. Consequently, one of the most popularly cited direct benefits of vehicle automation is better utilization of road space-both lateral and longitudinal [13]. Lateral space can be gained by narrowing lane widths to as low as $2.5 \mathrm{~m}$ [44], from the current standard of 3.4-3.7 $\mathrm{m}$ in Singapore, since AVs can drive more precisely. Longitudinal space can be gained by reducing the gap between vehicles. Humans should not drive with a time gap of less than $0.9 \mathrm{~s}$, and the legal recommendation is $2 \mathrm{~s}$, whereas an AV can drive with a 0.3-0.5 s gap, leading to more efficient use of longitudinal space [23].

The longitudinal gains in road capacity depend on road type and changes in demand. A mathematical model of the flow of purely autonomous traffic shows that street capacity can increase from $40 \%$ to $80 \%$ depending on the type of street [28]. Ambühl et al. [45] also find that road space needed can decrease by around 11-12\% only as a result of automation, serving the same number of trips. However, they also find that if the same road infrastructure is maintained, the total number of trips may potentially triple.

Further longitudinal capacity benefits can be drawn from CAVs. Tientrakool et al. [46] show that AVs equipped with sensors can increase highway capacity by $43 \%$, and those equipped with cooperative adaptive cruise control (CACC) can increase highway capacity by $273 \%$. It can be concluded that connected automated vehicles offer much more substantial gains in terms of road capacity than only AVs. However, these gains are contingent on the market penetration of the technology and the street type [47]. Connected vehicles can also dramatically increase intersection capacity, as discussed previously, rendering traffic signals obsolete and freeing up space at intersections.

Vehicle sharing may lead to fewer vehicles on the street overall, resulting in a further increase in longitudinal capacity. In all three simulation models of Ann Arbour, Babcock Ranch and Manhattan, Burns et al. [31] found that far fewer shared cars were needed to serve the same number of trips as privately owned vehicles. Alonso-Mora et al. [33], Fagnant and Kockelman's [35] and Spieser et al. [36] also reach the same conclusion from their studies in New York, Austin and Singapore, respectively. Hörl et al. [48] find that the fleet size required to serve all trips originating and ending in Zurich city could vary between 7000 to 14,000 , depending on the choice of operational policy, e.g., customer vehicle assignment, repositioning of empty vehicles, costs, etc.

The space required for parking can be significantly reduced through changes in parking infrastructure design for automated vehicles. Nourinejad et al. [49] use numerical 
modelling to test optimal parking layout for AVs and find that AV carparks can decrease the need for parking space by an average of $62 \%$ and a maximum of $87 \%$. As we move towards greater vehicle sharing, parking requirements would reduce even further. Agent-based simulations of Greenwich show that automated mobility on demand can reduce parking space requirement by 16-38\% due to reduction in trips that require parking [37]. Zhang et al. [50] use agent-based simulations and show up to $90 \%$ reduction in daily parking spaces required with shared autonomous vehicles' implementation at a penetration rate of as low as $2 \%$.

The technological shift will have a substantial impact on the overall footprint of the city, by influencing work and home location choices in the long term. Zakharenko [51] found a $7.1 \%$ increase in the urban land area in their location choice model, as a result of vehicle automation. The willingness to travel longer distances due to decreased value of travel time could increase the urban footprint, cancelling out the gains in longitudinal capacity. Gelauff et al. [52] also found similar effects in their simulations of a spatial general equilibrium model in the Dutch context. With only car automation, in-vehicle travel time becomes more productive, and it may lead to population flight from the cities, leading to dispersion. With public transit automation, coupled with door-to-door shared AV service, we can expect clustering of the population in urban areas, leading to concentration. A combination of the two leads to concentration of the population in the largest most attractive cities at the expense of smaller cities.

It is not clear if AVs increase or decrease road capacity, parking space requirement and urban footprint, and these effects depend on transport policy, urban planning, prevailing local conditions and operating model [53]. But it is clear that space benefits can only be maximized when connected and shared mobility is fully embraced, and vehicle automation reaches significant market penetration rates. The impacts of the shift on space use vis a vis various external driving factors and starting conditions are summarized in Appendix B Figure A2.

\subsection{Will the Shift Increase or Decrease Traffic-Based Emissions?}

This theme lends itself best to quantitative analysis, and several computational models have been built to predict the environmental impacts of the technological shift in transportation. Automation is expected to improve fuel economy through 'eco-driving', a set of practices that can decrease fuel consumption, without any changes in vehicle design, for example, driving at moderate speeds yields best engine efficiency or minimizing braking and acceleration cycles. Wadud et al. [11] find a reduction in energy consumption between $5 \%$ and $20 \%$, with lower impact when we begin high initial level of congestion. On the other hand, vehicles may drive at a much higher speed than today to save time, which could lead to about 7-22\% higher fuel consumption for light-duty vehicles on highways [11].

Platooning is another mechanism through which energy consumption can be reduced. As vehicles drive in tightly packed platoons, the aerodynamic drag is reduced. The longer the platoon, the higher the drag reduction and hence, energy saving. Wadud et al. [11] find that if platooning were universally adopted on highways by light-duty vehicles, energy consumption may decrease by $3-25 \%$. Brown et al. [43] find a reduction of $10 \%$ due to platooning, but an almost $40 \%$ reduction can be achieved if stopping and braking at intersections is eliminated altogether. The real benefits of platooning cannot be realized unless stopping and braking instances are minimized, and the length of the platoon is maximized, which would be detrimental to cycling and walking. Additionally, there is a trade-off between high vehicle speeds and rider comfort in a platoon. According to a traffic micro-simulation study, if a platoon has to match the rider comfort of a high-speed train, the delay can constitute up to $10 \%$ of travel time [54].

The impact of vehicle electrification on emissions is generally very positive. An agentbased simulation of Manhattan shows that replacing personal vehicles with short-range SEAVs could reduce greenhouse gas emissions by more than half [32]. When we compare the combined effect of electrification and vehicle sharing with personal electric vehicles serving the same number of trips, the GHG emissions can be reduced by more than half. 
Connected vehicles will also be better routed, selecting the most efficient route to avoid traffic, reducing energy consumption by up to $5 \%$ [43]. However, a recent study that takes an integrated approach to evaluate the lifecycle of greenhouse gas (GHG) emissions of electric AVs at the urban mobility level presents a contradicting viewpoint, pointing towards the negative environmental impacts of the Li-ion batteries process (production, intervention of replacement and end-of-life treatment) [55].

Tailored vehicles are another mechanism to reduce fuel consumption. A self-driving car is expected to be much safer than a human-driven one, which may eventually lead to a smaller and lighter vehicle. A tailored vehicle that can potentially shed the extra weight of safety equipment would lead to a reduction of about $5 \%$ in fuel consumption according to a study [11], and up to 50\% according to Brown et al. [43], depending in other enabling technologies.

These vehicles can be further 'right-sized' with increased vehicle sharing and better utilization of vehicle fleet. For example, average usage times of private cars in Switzerland per day is $1.32 \mathrm{~h}$, but could increase by a factor of 2 to 7 when shared vehicles are introduced, irrespective of the fleet size [56]. Similarly, Martinez and Viegas [57] find that vehicles are used much more intensely, from approximately $50 \mathrm{~min}$ per day today, to 12 hours per day in an agent-based simulation of SAVs in Lisbon. High intensity of use reduces the operating lifecycles, allowing quicker renewal of fleets, resulting in a younger and environmentally cleaner fleet.

Vehicle sharing will also lead to fewer vehicle kilometers travelled, which can be taken as a proxy for emissions. According to an agent-based simulation of Lisbon, if all private vehicles and bus services were to be replaced by shared AVs, carbon emissions would decrease by almost $40 \%$ in the most favorable scenario [57]. In a simulation of Zug, Bösch et al. [58] find a $12.4 \%$ change in mode share, switching from private cars to automated taxis, reducing the overall number of vehicles.

However, there are some caveats to these gains from vehicle sharing. Becker et al. [38] simulate SAVs in Zurich and find that ride-hailing increases energy consumption by competing with transit and active mobility. They suggest that making agents consider the social cost of their car trip can help to reduce transport-related energy consumption by almost $25 \%$. A similar suggestion is made by Childress et al. [41], based on an activitybased model of Seattle. They find that if self-driving cars are priced per mile, VKT could be reduced, by as much as 20\%. Fagnant and Kockelman [35] also observe an overall reduction in VKT in their simulation study of Austin, contingent on a greater emphasis on ride-sharing. However, in a simulation model for Singapore in 2030, Oh et al. [59] find that introduction of automated mobility on demand significantly increases VKT by up to $17 \%$, which could be because Singapore already has high share of public transit and shared mode usage $(\sim 66 \%)$. In this case, the increase in VKT can be mitigated if the overall vehicle fleet is kept fixed. Thus, pricing and operational policy are key determinants for the environmental impacts of SAVs.

Contrary to the studies discussed so far, some studies predict an increase in VKT with SAV implementation, as result of increase in empty rides and changes in mode choice. In their simulation study of Singapore, Spieser et al. [36] find that although SAVs provide mobility to the entire population with far fewer vehicles, these vehicles also end up travelling more. In the agent-based simulation of Greenwich, Segui-Gasco et al. [37] observe that the total number of vehicle kilometers driven by the shared $\mathrm{AV}$ fleet increases by $57 \%$, leading to a $24 \%$ increase in carbon emissions. Similarly, Ambühl et al. [45] find that although vehicle automation can reduce road space required by $11-12 \%$, if the given road infrastructure remains as is, it may triple the total number of trips due to induced demand.

The impact of the addition of latent demand and induced demand on emissions can be significant and may even eclipse the gains from eco-driving and electrification. According to a location choice modelling study by Zakharenko [51], even though the urban footprint area increases by $7 \%$ due to automation, the overall congestion may not increase since AVs 
are expected to operate more efficiently. On the other hand, according to an agent-based simulation of Greenwich, although travel times for private car users are reduced by $4 \%$, emissions increase by $24 \%$ because of the overall increase in distances driven.

These effects due to induced and latent demand are significant but unclear at the moment based on these contradictory results. From the agent-based simulation of Zug, Bösch et al. [58] conclude that vehicle automation could reduce energy use and greenhouse gas emissions by half in an optimistic scenario or double them in a 'dystopian nightmare'. It is clear that vehicle automation does not automatically result in reductions in energy consumption and emissions, but it indirectly supports changes in vehicle operations, vehicle design, choice of energy, policy intervention, or transportation system design that may or may not be more sustainable. These impacts and the levers and drivers that influence them are summarized in Appendix B Figure A3.

\subsection{Will the Shift Threaten Transit and Active Mobility or Strengthen It?}

Transit cannot compete with the flexibility of the automobility system, but shared automated vehicles offer the possibility to close the gap between traditional fixed-route transit and the private automobile. They facilitate flexibility in the time of arrival, offering different levels of privacy, route options and vehicle size options. In an agent-based simulation of Lisbon with only rail-based transport and shared taxis (4-16 seater), a vast improvement in access to jobs for public transit users was observed [57]. Meyer et al. [42] also find gains in accessibility in their model of SAV deployment in Switzerland. However, these gain are distributed unevenly. While rural areas experience significant gains, in the larger cities, the additional demand outweighs the capacity benefits, leading to an increase in travel times and therefore lower accessibilities. This observation is consistent with Luo et al.'s simulation study of Gunma prefecture in Japan [60].

SAVs can provide similar levels of access as a private car to everyone, depending on the urban context of operation, but they may also reduce the ridership of traditional transit. In agent-based simulations of SAVs in Greenwich, although private car use reduced by $6-15 \%$, bus trips are also reduced by $8-34 \%$ [37]. Based on an agent-based simulation model of Singapore for 2030, Oh et al. [59] find that use of automated shared mobility is likely to be higher than that of existing taxi services (even at comparable prices), with a substantial proportion of new users shifting from public transit. Becker et al. [38] simulated SAVs and shared e-bikes in Zurich and observed that the presence of small car-sharing and ride-hailing fleets increased the demand for bike-sharing, whereas competition by large car-sharing fleets reduced it. In contrast, the presence of a small bike-sharing schemes lowers the demand for car-sharing, but larger bike fleets increase it. These conclusions highlight the potential threat from new services to core public transport patronage and active mobility.

Most studies in the area of active mobility and automated vehicles focus on the behavioral interaction aspects (see Rasouli and Tsotos [61] for a summary), using methods such as interviews and surveys. For example, Booth et al.'s [62] online survey revealed that a significant number of Australians would be likely to use AVs instead of walking (18\%), cycling (32\%) and public transport (48\%).

There are two views on the impact of the technological shift in transportation on active mobility. Proponents speculate that vehicle automation should efficiently integrate cars with non-motorized modes of transport like walking and cycling, by reducing intimidation by cars [63]. But many scholars hold an opposing view based on several considerations. AVs and pedestrians are considered fundamentally incompatible, based on their differing goals.

For example, Fernandes and Nunes [64] find that platooning may increase road capacity by almost five times, but these capacity benefits may not be entirely realized since the complex, unpredictable movements of city traffic, cyclists and pedestrians can make platooning much more difficult. In order to create efficient platoons, they need to be entirely separated from the rest of the traffic, through barriers or grade separation [3]. 
Millard-Ball [65] uses game theory to analyze the interactions between pedestrians and AV when they are not separated through grade. He finds that pedestrians can behave with impunity since AVs are more risk-averse than human drivers, and may be more inclined to jaywalk, thus slowing traffic down. A summary of the impacts of the technological shift on transit use and active mobility can be found in Appendix B Figure A4.

\subsection{Will the Shift Increase or Decrease the Cost of Travel?}

An unresolved aspect of the technological shift is, who pays for the roads? [13] Taxes, fees and tolls from private automobile users contribute significantly to road construction budgets. Loss of this revenue stream, combined with the loss of revenue from parking, is a matter of concern for transportation authorities. This loss of revenue may be supplemented by the reduction in proposed road expansion investments as platooning and eco-driving could increase road capacity by as much as five times [64].

Although AV technologies may raise the initial purchase price of a vehicle, reduction in operating cost through lower insurance fees, maintenance and reduced fuel costs due to eco-driving may balance this out. However, according to Brown et al. [43], fuel costs may also increase due to an increase in the overall number of kilometers driven as a result of induced demand. To counter this, Childress et al. [41] test pricing of self-driving cars per mile, in an activity-based model of Seattle. Both vehicle kilometers travelled and vehicle hours travelled could be significantly reduced, by as much as $20 \%$ and $30 \%$ respectively, with transit shares almost doubling.

Shared AV implementations are expected to result in further cost benefits by eliminating the cost of drivers. According to a detailed cost model of Switzerland, autonomous driving technology allows taxi services and buses to operate at a substantially lower cost, even cheaper than private cars. In relative terms, automated taxis will be only $71 \%$ more expensive for an individual, and 21\% more expensive for pooled use than automated buses (compared to $415 \%$ and $204 \%$ before automation) [66]. According to a cost model of Shared AV implementation in Zug built by Sinner et al. [67], the operating costs of bus networks can be reduced by $50 \%$ to $60 \%$ through automation. A simulation of SAVs in Paris shows an operating cost of $0.27 \mathrm{EUR} / \mathrm{km}$, which is lower than the full cost of owning a private vehicle [56]. However, a simulation of an automated taxi system in Zurich shows that while such a system can be beneficial for the users monetarily, the system's impact is largely negative due to the modal shift from transit to door-to-door AV taxis [68].

Trade-offs between monetary travel costs, the value of time and customer acceptance, as well as additional parameters such as investment, maintenance cost and fleet size, need to be explored. For example, increasing battery range, charging speed and the density of chargers can decrease the number of vehicles required but also increase other costs. In an agent-based simulation of Manhattan, the estimated cost for the operation of an SEAV fleet is roughly ten times lower than a regular taxi fare, as a result of savings due to electrification, the elimination of driver cost and efficiency of a single-operator, smartphonebased system [32]. Zhai et al. compare a traditional bus system with an automated bus on-demand $(\mathrm{ABOD})$ system and find that if the travel demand exceeds five multiples of the current demand, the total cost of conventional buses increases sharply, while the cost of the $\mathrm{ABoD}$ increases almost linearly, which indicates that the ABoD system is more adaptive to the change in travel demand than the conventional buses [24].

It is important to account for differences in local contexts when evaluating the economic benefits of the technological shift in transportation. Becker et al. [69] conducted a comparative study of cost benefits of vehicle automation and electrification for 17 cities, and found that high-income countries benefit most from these technologies, due to the different relative contribution of labor cost to the total taxi/bus operating cost. The benefits of vehicle automation are greater in countries where drivers' salaries are larger. Even so, this carries the risk of increase in congestion and emissions, as taxi services are expected to become the preferred mode with plummeting production costs. 
One unexpected outcome of vehicle automation could be inequity in real estate values. According to simulations of the Dutch Spatial General Equilibrium Model, car automation alone will result in population flight from cities and convergence of residential prices between cities and rural areas. However, public transport automation has the opposite effect. It leads to further population clustering in urban areas, and an increase in residential price disparity between cities and rural areas [52]. Thus, several factors need to be considered to accurately predict the long-term economic impact of the technological shift. A summary of these factors can be found in Appendix B Figure A5.

\section{Conclusions}

This paper set out to understand if the technological shift in transportation will set cities on a path to sustainability by examining impacts in five areas-traffic flow, space consumption, emissions, transit and active mobility and cost of mobility. A review of quantitative studies on isolated impacts shows that the technological shift could be both beneficial and detrimental to our goals in all five areas of concern. Figures A1-A5 in Appendix B illustrate how the new capacities enabled by the technological shift (shown in blue text on white) can yield a myriad of results (shown in white text on blue), which can be both beneficial and harmful to our mobility goals. Figure 1 summarizes these capabilities and possible impacts.

\begin{tabular}{|c|c|c|c|}
\hline \multirow{2}{*}{\multicolumn{2}{|c|}{$\begin{array}{l}\text { Capabilities enabled by the } \\
\text { technological shift }\end{array}$}} & \multirow{2}{*}{\multicolumn{2}{|c|}{ Possible impacts }} \\
\hline & $\begin{array}{l}\text { ed by the } \\
\text { t }\end{array}$ & & \\
\hline \multicolumn{2}{|c|}{$\begin{array}{l}\text { Convenience and flexibility } \\
\text { Diverse choice of shared modes } \\
\text { Intelligent traffic management } \\
\text { Reduction of headways } \\
\text { Driving at higher speeds } \\
\text { Driving efficiently and 'eco-driving' } \\
\text { Reduction in overall vehicle stock } \\
\text { Increased in-vehicle productivity } \\
\text { Platooning } \\
\text { Better vehicle utilisation } \\
\text { Increased compliance } \\
\text { Reduction in operating cost (SAV) } \\
\text { New physical infrastructure } \\
\text { requirements (charging, sensors etc.) } \\
\text { New vehicle upgrade requirements } \\
\text { (sensors, cameras etc.) }\end{array}$} & \multicolumn{2}{|c|}{ 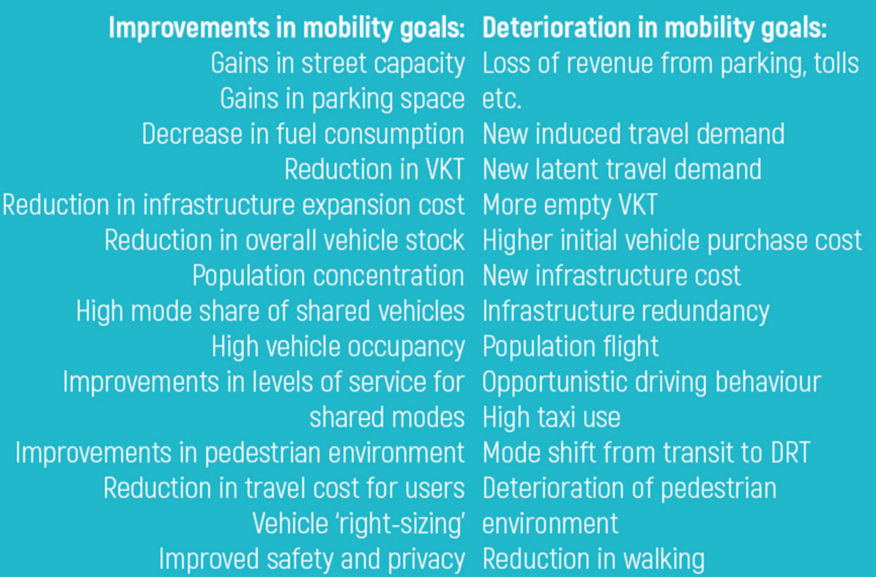 } \\
\hline \multicolumn{4}{|c|}{ Drivers and levers that influence impacts } \\
\hline $\begin{array}{l}\text { Technology } \\
\text { Technology readiness, } \\
\text { customer acceptance, } \\
\text { and technology } \\
\text { penetration rate in } \\
\text { the market. }\end{array}$ & $\begin{array}{l}\text { Policy } \\
\text { Policy on pricing, for example } \\
\text { minimum price for taxis to avoid } \\
\text { competition with transit, pricing } \\
\text { in the social cost of travel, } \\
\text { pricing by distance. } \\
\text { Subsidies of to protect transit } \\
\text { and shared modes. } \\
\text { Road pricing, curb use pricing } \\
\text { Limiting maximum fleet size, } \\
\text { geofencing operation area of AVs } \\
\text { Policies that encourage or } \\
\text { discourage the use of private } \\
\text { AVs vs shared AV fleets }\end{array}$ & $\begin{array}{l}\text { Operations } \\
\text { Shared vehicle operational } \\
\text { decisions such as customer } \\
\text { vehicle assignment, } \\
\text { repositioning of empty } \\
\text { vehicles, maximum allowable } \\
\text { waiting time, detour ratio for } \\
\text { shared vehicles, total fleet } \\
\text { size and type. } \\
\text { Electric vehicle operational } \\
\text { decisions such as type of } \\
\text { batteries, battery range, } \\
\text { density of charging points, } \\
\text { charging speeds. }\end{array}$ & $\begin{array}{l}\text { Planning } \\
\text { Existing urban context - level of } \\
\text { urbanisation, density, street hierarchy, level } \\
\text { of congestion, modal split, especially } \\
\text { current levels of transit use and transit } \\
\text { infrastructure development. } \\
\text { Design interventions - transit oriented } \\
\text { development, urban design for active } \\
\text { mobility, walkability, location, size and } \\
\text { frequency of PUDOs, parking infrastructure } \\
\text { design, design for segregation by mode, } \\
\text { design of street hierarchy and network } \\
\text { topology, intersection design }\end{array}$ \\
\hline
\end{tabular}

Figure 1. Summary of impacts of the technological and driving forces. 
On the one hand, the technological shift can be beneficial by potentially disrupting current automobile-dependent patterns of development. Automated vehicles drive more efficiently, have quicker reaction time and need shorter headways. Connected vehicles allow for better vehicle routing and avoidance of congestion. Vehicle sharing leads to a decrease in vehicle ownership rates. Tailored vehicles can rid themselves of additional safety gear like airbags, and be lighter and right-sized, leading to better fuel efficiency. A combination of these factors can lead to benefits such as better traffic mobility and road capacity gains (both lateral and longitudinal), fuel savings due to 'eco-driving', intersections and parking space savings, fewer vehicles to provide the same level of service, less congestion and safer, more pedestrian-friendly streets.

On the other hand, the technological shift can also be detrimental to future mobility goals, by furthering the car-oriented development patterns of today. Instead of practicing eco-driving, AVs may drive at higher speeds than today, leading to time gains, but more fuel consumption. Vehicle sharing may lead to fewer vehicles on streets, but detours and empty travel may increase congestion and fuel consumption. Change in value of in-vehicle travel time may lead to induced demand and changes in home and job location choices leading to urban sprawl. Latent demand from those sections of the population that are currently unable to drive will also add to the induced demand.

The impacts of the technological shift are uncertain and difficult to predict. Quantitative models only consider a limited parameter set, and the choice of parameters is highly subjective. This leads to highly divergent and often contradictory results. In this context, while it is difficult to predict the impacts of the technological shift, we have begun to identify the most influential drivers that can help us steer the impacts of the shift, based on the dynamics of the parameter choices in the simulation studies reviewed. Broadly, these drivers can be classified in four types: technology, policy, operations and planning. Appendix B summarizes the various drivers and levers within the four categories discussed here.

\section{Technology}

The first most influential driver will determine the impact of the shift of the level of technological, development, deployment and acceptance. The pace of technological development and integration of automation, electrification, vehicle-sharing and connectivity is a crucial factor in determining whether the shift can beneficially impact cities. For example, discussion of the impact of AVs on emissions is strongly linked to developments in electric propulsion, which is likely to precede automation. In addition, their rate of adoption and market penetration also needs to be high enough to draw any significant benefits [70], in each of the five areas studied here. The capabilities of AV, their uptake, charging infrastructure for electric vehicles, development in Artificial Intelligence and other new competing technologies are one of the most uncertain and significant driving forces of the technological shift. Studies that take into account the pace of development of the technological shift as a whole (such as Reference [5]), as well public acceptance of these technologies (such as Reference [70]) are essential and must precede quantitative analysis of any type of isolated impact.

\section{Policy}

The second most influential factor observed here is policy and regulatory actions. Proactive policy can help support rapid uptake of desirable technologies, such as electric vehicles and higher vehicle sharing, while reactive or inert actions may delay the process. Regulating policies revolve around issues such as testing and deployment, cybersecurity and privacy, liabilities and insurance, ethics, and most importantly, pricing and ownership. How self-driving cars will change cities depends on who owns them. More private ownership may lead to a dramatic increase in VKT, AV taxis may lead to inequitable access and a large public transit $\mathrm{AV}$ infrastructure requires huge investments and subsidies. The pressure for climate change action and resolution on sustainability and energy efficiency may 
lead to environmental regulations that would, in turn, determine the pace of technological development and uptake of technologies like electric vehicles and vehicle sharing.

Many of the initial parameter choices in the simulation studies are direct policy choices. While the first set of drivers relating to technology is largely market-driven, policymakers also play a substantial role in driving the overall outcome. Thus, it is imperative for policymakers to make priorities explicit and collectively set benchmarks for minimum levels of service with appropriate indicators to measure them.

\section{Operations}

Once automated vehicles are deployed and regulatory priorities set, the operational decision plays a key role in driving the impacts. Studies on the isolated impacts have shown that the fleet type and size of shared vehicles have a strong effect on mode choice, emissions and space consumption. Hörl et al. [48] calculate fleet size based on choice of operational policy such as customer vehicle assignment, repositioning of empty vehicles, costs, etc., and find a significant variation between 7000 to 14,000 vehicles. Trade-offs between monetary travel costs, the value of time and customer acceptance, as well as additional variables such as investment, maintenance cost and fleet size, are complex and need tailored analysis for different contexts. Pricing of automated vehicles and rides in shared automated services play an especially important role in influencing impacts in all five areas studies here.

\section{Planning}

Finally, given a high degree of automation and large-scale deployment, urban design and planning strategies will begin to play a more important role to steer the impacts by modifying travel behavior. Studies such as References [11,28] find different result in their models based on differences in existing planning contexts. Planning strategies, such as land use planning, urban network structure, type, size and age of existing urban fabric and scale of $\mathrm{AV}$ infrastructure implementation, can be effective levers to influence the impacts of the shift. The driving factors related to planning and design can only be tested in the long-term future when AV deployment is significant enough. The impacts of these drivers also lend themselves better to qualitative design-based studies.

Future research in this area needs to take into account the complex interplay of all the driving forces within the realm of technology, policy, operations and planning, to some extent. A quantitative model that can sufficiently address all these dynamics can be time-consuming and costly to build. At the same, the impacts of policy- and design-based drivers are harder to analyze through these methods. This points towards the need for innovations in modelling techniques, and better integration of quantitative methods of investigation with qualitative studies on impacts of AVs and other emerging transportation technologies.

Author Contributions: Conceptualization, T.M. and K.W.A.; Formal analysis, investigation, data curation, writing — original draft preparation, editing, visualization, T.M.; Writing—review, supervision, funding acquisition, K.W.A. All authors have read and agreed to the published version of the manuscript.

Funding: This material is based on research/work supported by the Singapore Ministry of National Development and National Research Foundation under L2NIC Award No. L2NICTDF1-2016-3. The research was conducted at the Future Cities Laboratory at the Singapore-ETH Centre, which was established collaboratively between ETH Zurich and Singapore's National Research Foundation (FI 370074016) under its Campus for Research Excellence and Technological Enterprise programme.

Institutional Review Board Statement: Not applicable.

Informed Consent Statement: Not applicable.

Data Availability Statement: No new data were created or analyzed in this study. Data sharing is not applicable to this article. 
Acknowledgments: This research is part of a larger research project which would not have been possible without the contributions of Pieter Fourie, Stephen Cairns, Alexander Erath and Sergio A. Ordoñez Medina. Contributions from collaborating institutes, including SMART MIT and National University Singapore, as well as agencies (URA, LTA, HDB, Ministry of Transport, Singapore) are also acknowledged by the authors.

Conflicts of Interest: The authors declare no conflict of interest. The funders had no role in the design of the study; in the collection, analyses, or interpretation of data; in the writing of the manuscript, or in the decision to publish the results.

\section{Appendix A}

This review is based on an analysis of peer-reviewed studies published between 2011 and 2020 that analyze the impacts of vehicle automation technology in isolation or in combination with other technologies, such as adaptive cruise control, electrification or shared demand responsive transit. Three databases, ScienceDirect, Springer and IEEE Xplore were first searched. This was supplemented by a Google Scholar search that also encompasses books and conference papers, and forward and backward snowball techniques. A combinations of three keyword sets was used. The first set related to technology: automated vehicles, autonomous vehicles, driverless vehicles, shared vehicles, shared automated vehicles, Demand Responsive Transit (DRT), electric automated vehicles, connected automated vehicles and vehicle to vehicle connectivity. The second set related to methods: mathematical modelling, simulation and quantitative analysis. The third set included themes such as impacts, implications, effects, cities, energy, congestion, cost, space and value of travel time. An initial shortlist was prepared to include papers using quantitative methods only, studying isolated impacts, and primarily studying AV technology in isolation or in combination with other technologies. This selection was finally filtered to include a diversity of methods, vehicle technology combinations and geographic locations.

Table A1. The thirty-four studies reviewed in this paper are described here.

\begin{tabular}{|c|c|c|c|}
\hline $\begin{array}{c}\text { Study } \\
\text { Reference }\end{array}$ & Location & Method & Vehicles \\
\hline [46] & No geographic location & Mathematical Modelling & CAV only \\
\hline [31] & $\begin{array}{l}\text { Ann Arbour, Babcock } \\
\text { Ranch, Manhattan }\end{array}$ & Analytical Modelling and Simulations & SAV only with small vehicles \\
\hline [47] & No geographic location & Microscopic Simulation & CAV in mixed traffic \\
\hline [25] & No geographic location & Microscopic Simulation & CAV in mixed traffic \\
\hline [43] & No geographic location & Mathematical Modelling & $\begin{array}{l}\text { Location agnostic estimation of impacts } \\
\text { of automation, connectivity, sharing and } \\
\text { electrification. }\end{array}$ \\
\hline [71] & New Jersey & Mathematical Modelling & Autonomous taxi network \\
\hline [36] & Singapore & Mathematical Modelling & $\begin{array}{l}\text { Replacing all private vehicle with small } \\
\text { SAV }\end{array}$ \\
\hline [41] & Puget Sound Region & Activity-based Simulation & $\begin{array}{l}\text { All vehicle types automated with varying } \\
\text { technology penetration rates }\end{array}$ \\
\hline [64] & No geographic location & Agent-based Simulation & CAV on dedicated tracks \\
\hline [27] & No geographic location & Microscopic Simulation & AV and CAV only \\
\hline [50] & No geographic location & Agent-based Simulation & SAV replace $2 \%$ of private vehicles \\
\hline [45] & No geographic location & $\begin{array}{l}\text { Macroscopic Fundamental Diagram and } \\
\text { Mesoscopic Traffic Simulation }\end{array}$ & CV only and AV only \\
\hline [35] & Austin, Texas & Agent-based Simulation & $\begin{array}{l}\text { SAV for dynamic ridesharing as } \\
\text { additional mode }\end{array}$ \\
\hline [28] & No geographic location & Mathematical Model of Traffic flow & $\begin{array}{l}\text { Location agnostic estimation of impacts } \\
\text { of automation on flow }\end{array}$ \\
\hline [72] & United States & Mathematical Analysis & Automation of private vehicles \\
\hline
\end{tabular}


Table A1. Cont.

\begin{tabular}{|c|c|c|c|}
\hline $\begin{array}{c}\text { Study } \\
\text { Reference }\end{array}$ & Location & Method & Vehicles \\
\hline$[11]$ & United States & Mathematical Analysis & $\begin{array}{l}\text { Estimation of impacts of automation, } \\
\text { connectivity, sharing and electrification. }\end{array}$ \\
\hline [23] & Braunschweig & Microscopic Simulation & All passenger vehicles as $\mathrm{AV}$ \\
\hline [51] & No geographic location & Location Choice Modelling & $\begin{array}{l}\text { Private and Shared AV as additional } \\
\text { modes }\end{array}$ \\
\hline [55] & Rome & Traffic Simulation & All vehicles fully automated and electric \\
\hline [52] & The Netherlands & Simulations & All vehicles automated (cars and transit) \\
\hline [57] & Lisbon, Portugal & Agent-based Simulations & Shared automated taxis and minibuses \\
\hline [42] & Switzerland & Mathematical Modelling & $\begin{array}{l}\text { All vehicles automated with or without } \\
\text { sharing }\end{array}$ \\
\hline [66] & Switzerland & Cost Model & $\begin{array}{l}\text { Location agnostic study of cost changes } \\
\text { with automation for private vehicles, } \\
\text { taxis and public transport }\end{array}$ \\
\hline [32] & Manhattan & Agent-based Simulation & SEAV fleet as taxis \\
\hline [58] & Zug, Switzerland & Agent-based Simulation with MATSim & Combination of shared and private $\mathrm{AVs}$ \\
\hline [67] & Zug, Switzerland & Cost Model & AV Buses \\
\hline [38] & Zurich & Agent-based Simulation with MATSim & $\begin{array}{l}\text { SAV with options for carsharing and } \\
\text { ride-hailing + E-bikes }\end{array}$ \\
\hline [56] & Paris & Agent-based Simulation with MATSim & $\begin{array}{c}\text { Automated mobility on demand with } \\
\text { varying vehicle sizes determined } \\
\text { heuristically }\end{array}$ \\
\hline [68] & Zurich & Agent-based Simulation with MATSim & $\begin{array}{l}\text { Automated mobility on demand as an } \\
\text { additional mode }\end{array}$ \\
\hline [37] & Greenwich, UK & Agent-based Simulations & AVs as taxis and for pooled rides \\
\hline [26] & No geographic location & Microscopic traffic simulations & AVs with varying levels of automation \\
\hline [59] & Singapore & Agent based simulations & $\begin{array}{c}\text { Automated mobility on demand as an } \\
\text { additional mode }\end{array}$ \\
\hline [60] & Gunma, Japan & Agent-based Simulation with MATSim & SAV and PAV as additional modes \\
\hline$[24]$ & Fuyang, Zheijiang, China & Agent-based Simulations & $\mathrm{ABoD}$ as additional mode \\
\hline
\end{tabular}

PAV: Private Automated Vehicles; CAV: Connected Automated Vehicles; SAV: Shared Automated Vehicles; SEAV: Shared Electric Automated Vehicles, ABoD: Autonomous Bus on Demand. 


\section{Appendix B}

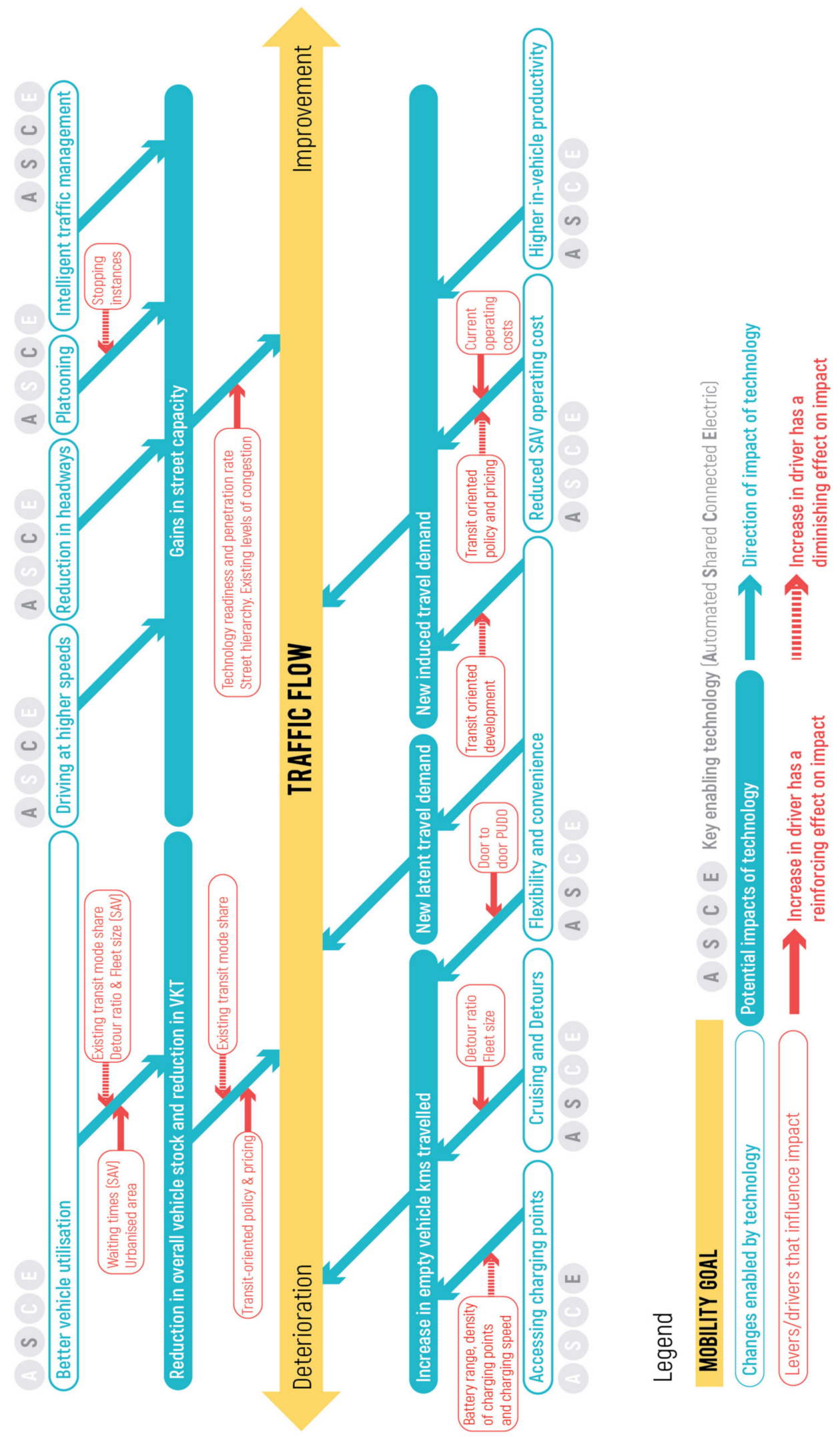

Figure A1. Impact of the technological shift on traffic flow: summary of results. 


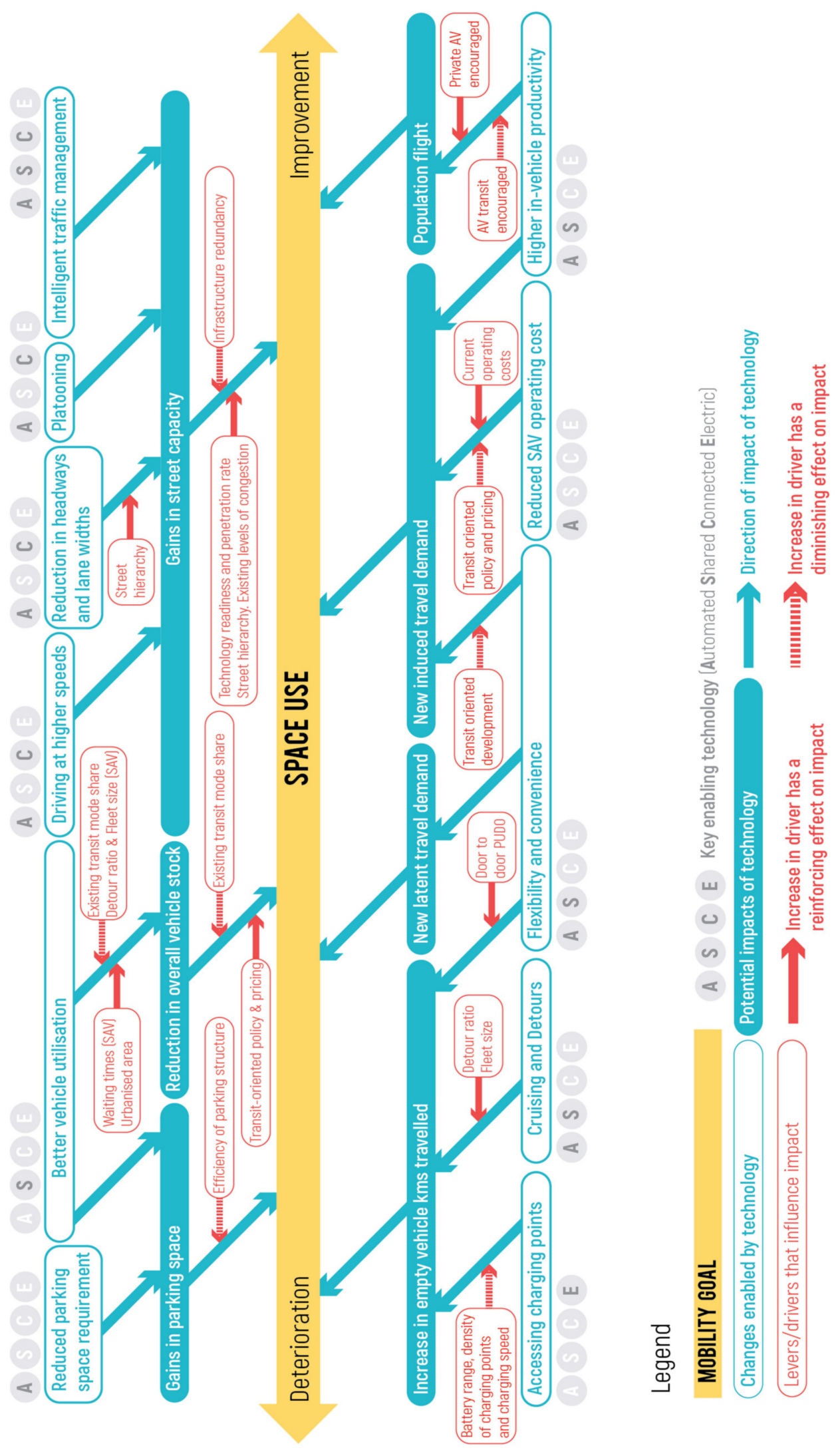

Figure A2. Impact of the technological shift on space use: summary of results. 


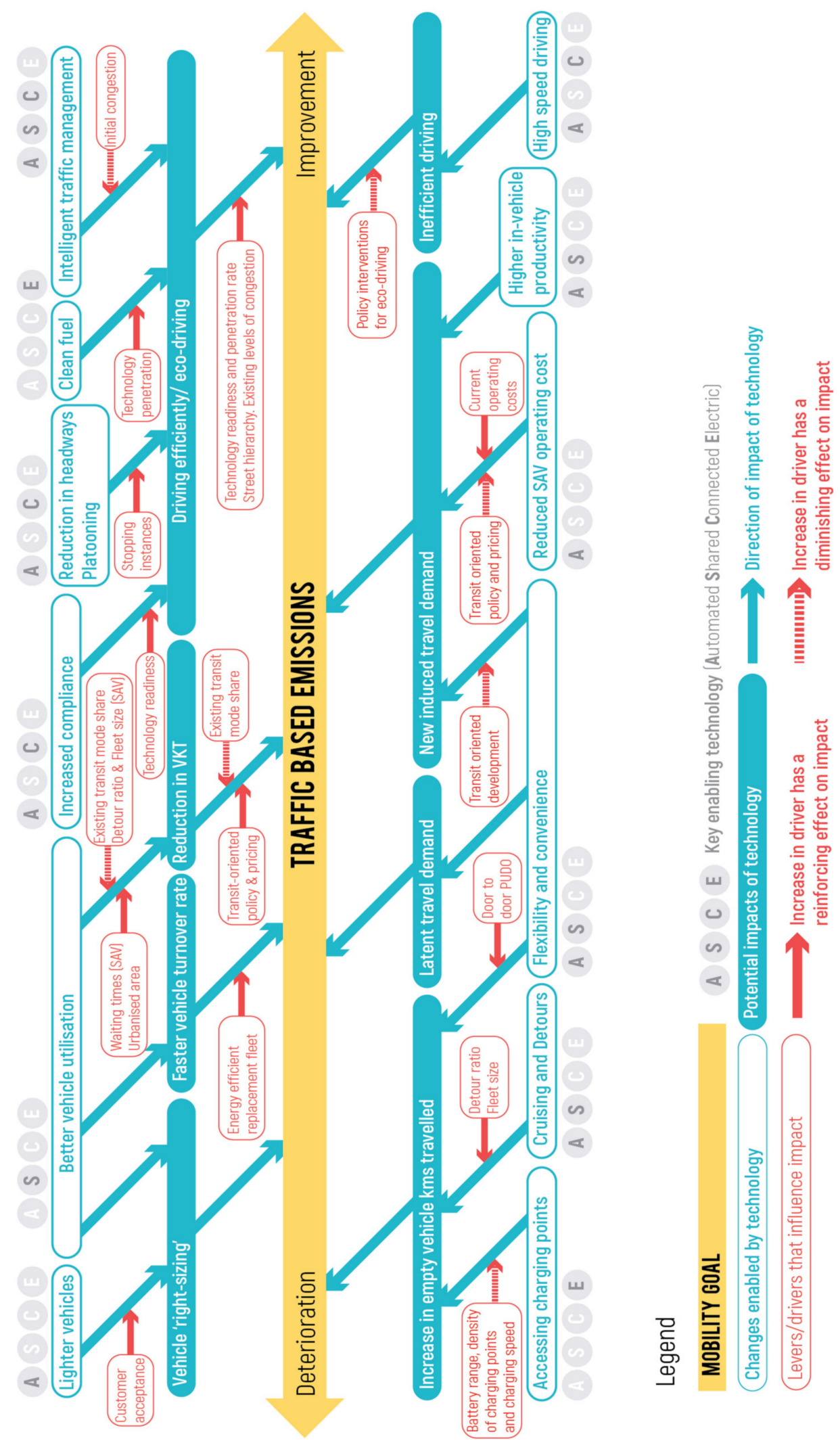

Figure A3. Impact of the technological shift on traffic-based emissions: summary of results. 


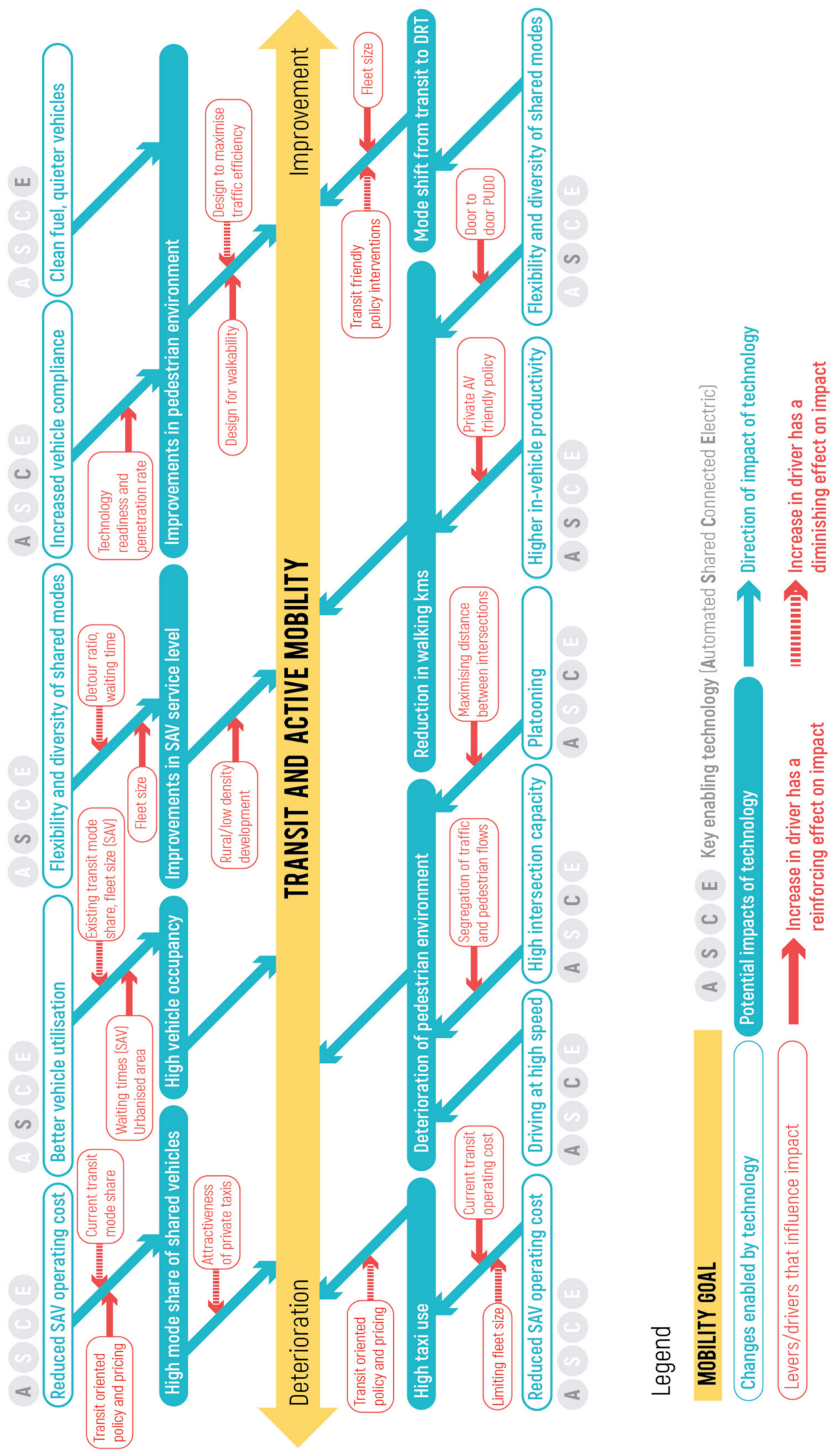

Figure A4. Impact of the technological shift on transit and active mobility: summary of results. 


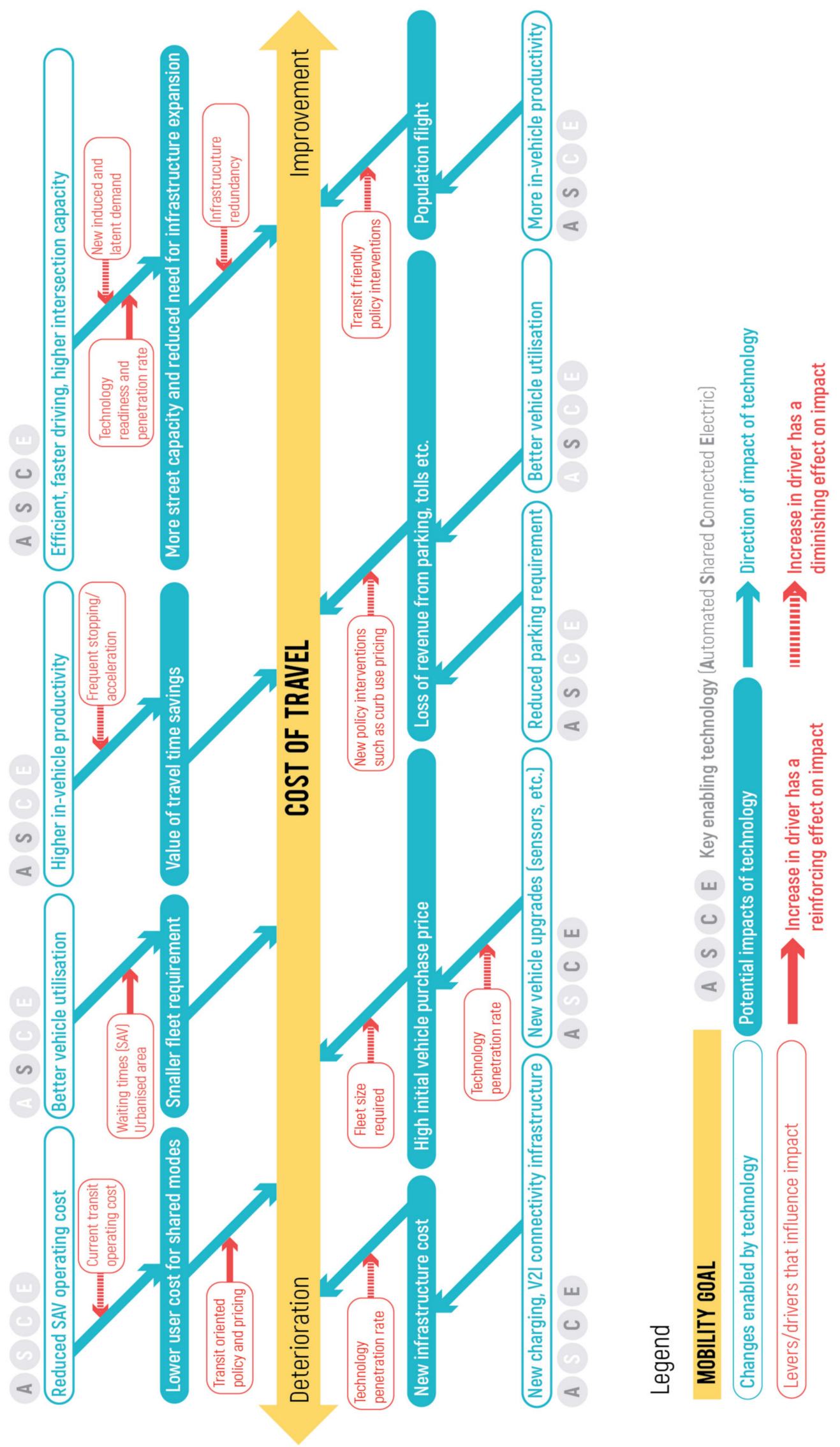

Figure A5. Impact of the technological shift on cost of travel: summary of results. 


\section{References}

1. Faisal, A.; Yigitcanlar, T.; Kamruzzaman, M.; Paz, A. Mapping Two Decades of Autonomous Vehicle Research: A Systematic Scientometric Analysis. J. Urban Technol. 2020, 1-30. [CrossRef]

2. The Aspen Institute Bloomberg Aspen Initiative on Cities and Autonomous Vehicles. Available online: http://avsincities. bloomberg.org/ (accessed on 27 October 2017).

3. Litman, T. Autonomous Vehicle Implementation Predictions: Implications for Transport Planning; Victoria Transport Policy Institute: Victoria, BC, Canada, 2021.

4. Anderson, M. The Road Ahead for Self-Driving Cars: The AV Industry Has Had to Reset Expectations, as It Shifts Its Focus to Level 4 Autonomy. IEEE Spectr. 2020, 57, 8-9. [CrossRef]

5. Nikitas, A.; Michalakopoulou, K.; Njoya, E.T.; Karampatzakis, D. Artificial Intelligence, Transport and the Smart City: Definitions and Dimensions of a New Mobility Era. Sustainability 2020, 12, 2789. [CrossRef]

6. Attias, D. The Automobile Revolution: Towards a New Electro-Mobility Paradigm; Springer: Berlin/Heidelberg, Germany, 2016; ISBN 978-3-319-45838-0.

7. Feng, S.; Magee, C.L. Technological Development of Key Domains in Electric Vehicles: Improvement Rates, Technology Trajectories and Key Assignees. Appl. Energy 2020, 260, 114264. [CrossRef]

8. Ge, X.; Li, Z.; Li, S. 5G Software Defined Vehicular Networks. IEEE Commun. Mag. 2017, 55, 87-93. [CrossRef]

9. Szalay, Z.; Ficzere, D.; Tihanyi, V.; Magyar, F.; Soós, G.; Varga, P. 5G-Enabled Autonomous Driving Demonstration with a V2X Scenario-in-the-Loop Approach. Sensors 2020, 20, 7344. [CrossRef]

10. Greenblatt, J.B.; Shaheen, S. Automated Vehicles, On-Demand Mobility, and Environmental Impacts. Curr. Sustain. Renew. Energy Rep. 2015, 2, 74-81. [CrossRef]

11. Wadud, Z.; MacKenzie, D.; Leiby, P. Help or Hindrance? The Travel, Energy and Carbon Impacts of Highly Automated Vehicles. Transp. Res. 2016, 86, 1-18. [CrossRef]

12. Fagnant, D.J.; Kockelman, K. Preparing a Nation for Autonomous Vehicles: Opportunities, Barriers and Policy Recommendations. Transp. Res. 2015, 77, 167-181. [CrossRef]

13. Sperling, D. Three Revolutions: Steering Automated, Shared, and Electric Vehicles to a Better Future; Island Press: Washington, DC, USA, 2018; ISBN 978-1-61091-905-0.

14. Dresner, S. The Principles of Sustainability; Earthscan: London, UK, 2008; ISBN 978-1-84407-706-9.

15. Richardson, B.C. Sustainable Transport: Analysis Frameworks. J. Transp. Geogr. 2005, 13, 29-39. [CrossRef]

16. Richardson, B.C. Toward a Policy on a Sustainable Transportation System. Transp. Res. Rec. 1999, 1670, 27-34. [CrossRef]

17. Yigitcanlar, T.; Dur, F. Developing a Sustainability Assessment Model: The Sustainable Infrastructure, Land-Use, Environment and Transport Model. Sustainability 2010, 2, 321-340. [CrossRef]

18. United Nations Department of Economic and Social Affairs. The Sustainable Development Goals Report 2018; United Nations Department of Economic and Social Affairs: New York, NY, USA, 2018.

19. European Commision. Urban Agenda for the EU Partnership for Urban Mobility-Action Plan; European Commission: Brussels, Belgium, 2018.

20. Papa, E.; Ferreira, A. Sustainable Accessibility and the Implementation of Automated Vehicles: Identifying Critical Decisions. Urban Sci. 2018, 2, 5. [CrossRef]

21. Chen, S.-Y.; Kuo, H.-Y.; Lee, C. Preparing Society for Automated Vehicles: Perceptions of the Importance and Urgency of Emerging Issues of Governance, Regulations, and Wider Impacts. Sustainability 2020, 12, 7844. [CrossRef]

22. Stead, D.; Vaddadi, B. Automated Vehicles and How They May Affect Urban Form: A Review of Recent Scenario Studies. Cities 2019, 92, 125-133. [CrossRef]

23. Wagner, P. Traffic Control and Traffic Management in a Transportation System with Autonomous Vehicles. In Autonomous Driving; Maurer, M., Gerdes, J.C., Lenz, B., Winner, H., Eds.; Springer: Berlin/Heidelberg, Germany, 2016; pp. 301-316. ISBN 978-3-662-48845-4.

24. Zhai, Z.; Yang, Y.; Shen, Y.; Ji, Y.; Du, Y. Assessing the Impacts of Autonomous Bus-on-Demand Based on Agent-Based Simulation: A Case Study of Fuyang, Zhejiang, China. J. Adv. Transp. 2020, 2020, e7981791. [CrossRef]

25. Arnaout, G.M.; Arnaout, J.-P. Exploring the Effects of Cooperative Adaptive Cruise Control on Highway Traffic Flow Using Microscopic Traffic Simulation. Transp. Plan. Technol. 2014, 37, 186-199. [CrossRef]

26. Xie, H.; Tanin, E.; Karunasekera, S.; Qi, J.; Zhang, R.; Kulik, L.; Ramamohanarao, K. Quantifying the Impact of Autonomous Vehicles Using Microscopic Simulations. In Proceedings of the 12th ACM SIGSPATIAL International Workshop on Computational Transportation Science, Chicago, IL, USA, 5 November 2019; pp. 1-10.

27. Le Vine, S.; Zolfaghari, A.; Polak, J. Autonomous Cars: The Tension between Occupant Experience and Intersection Capacity. Transp. Res. 2015, 52, 1-14. [CrossRef]

28. Friedrich, B. The Effect of Autonomous Vehicles on Traffic. In Autonomous Driving: Technical, Legal and Social Aspects; Maurer, M., Gerdes, J.C., Lenz, B., Winner, H., Eds.; Springer: Berlin/Heidelberg, Germany, 2016; pp. 317-334. ISBN 978-3-662-48847-8.

29. Tachet, R.; Santi, P.; Sobolevsky, S.; Reyes-Castro, L.I.; Frazzoli, E.; Helbing, D.; Ratti, C. Revisiting Street Intersections Using Slot-Based Systems. PLoS ONE 2016, 11, e0149607. [CrossRef] 
30. Jaffe, E. These Futuristic Driverless Car Intersections Forgot About Pedestrians and Cyclists—CityLab. Available online: http:// www.citylab.com/tech/2015/06/these-futuristic-driverless-car-intersections-forgot-about-pedestrians-and-cyclists /394847/ (accessed on 9 May 2016).

31. Burns, L.D.; Jordan, W.C.; Scarborough, B.A. Transforming Personal Mobility; The Earth Institute, Columbia University: New York, NY, USA, 2012.

32. Bauer, G.S.; Greenblatt, J.B.; Gerke, B.F. Cost, Energy, and Environmental Impact of Automated Electric Taxi Fleets in Manhattan. Environ. Sci. Technol. 2018, 52, 4920-4928. [CrossRef]

33. Alonso-Mora, J.; Samaranayake, S.; Wallar, A.; Frazzoli, E.; Rus, D. On-Demand High-Capacity Ride-Sharing via Dynamic Trip-Vehicle Assignment. Proc. Natl. Acad. Sci. USA 2017, 114, 462-467. [CrossRef]

34. Boesch, P.M.; Ciari, F.; Axhausen, K.W. Autonomous Vehicle Fleet Sizes Required to Serve Different Levels of Demand. Transp. Res. Rec. 2016, 2542, 111-119. [CrossRef]

35. Fagnant, D.J.; Kockelman, K.M. Dynamic Ride-Sharing and Fleet Sizing for a System of Shared Autonomous Vehicles in Austin, Texas. Transportation 2016, 45, 143-158. [CrossRef]

36. Spieser, K.; Treleaven, K.; Zhang, R.; Frazzoli, E.; Morton, D.; Pavone, M. Toward a Systematic Approach to the Design and Evaluation of Automated Mobility-on-Demand Systems: A Case Study in Singapore. In Road Vehicle Automation; Lecture Notes in Mobility; Meyer, G., Beiker, S., Eds.; Springer International Publishing: Cham, Switzerland, 2014; pp. 229-245. ISBN 978-3-319-05990-7.

37. Segui-Gasco, P.; Ballis, H.; Parisi, V.; Kelsall, D.G.; North, R.J.; Busquets, D. Simulating a Rich Ride-Share Mobility Service Using Agent-Based Models. Transportation 2019, 46, 2041-2062. [CrossRef]

38. Becker, H.; Balac, M.; Ciari, F.; Axhausen, K.W. Assessing the Welfare Impacts of Shared Mobility and Mobility as a Service (MaaS). Transp. Res. 2019, 131, 228-243. [CrossRef]

39. Lyons, G.; Urry, J. Travel Time Use in the Information Age. Transp. Res. 2005, 39, 257-276. [CrossRef]

40. Malokin, A.; Circella, G.; Mokhtarian, P.L. How Do Activities Conducted While Commuting Influence Mode Choice? Testing Public Transportation Advantage and Autonomous Vehicle Scenarios. In Proceedings of the TRB 94th Annual Meeting, Washington, DC, USA, 11-15 January 2015.

41. Childress, S.; Nichols, B.; Charlton, B.; Coe, S. Using an Activity-Based Model to Explore Possible Impacts of Automated Vehicles. Transp. Res. Rec. 2015, 2493, 99-106. [CrossRef]

42. Meyer, J.; Becker, H.; Bösch, P.M.; Axhausen, K.W. Autonomous Vehicles: The next Jump in Accessibilities? Res. Transp. Econ. 2017, 62, 80-91. [CrossRef]

43. Brown, A.; Gonder, J.; Repac, B. An Analysis of Possible Energy Impacts of Automated Vehicles. In Road Vehicle Automation; Lecture Notes in Mobility; Springer: Cham, Switzerland, 2014; pp. 137-153. ISBN 978-3-319-05989-1.

44. Schlossberg, M.; Riggs, W.; Millard-Ball, A.; Shay, E. Rethinking the Street in an Era of Driverless Cars; Urbanism Next; University of Oregon: Eugene, OR, USA, 2018.

45. Ambühl, L.; Ciari, F.; Menendez, M. What about Space? A Simulation Based Assessment of AVs Impact on Road Space in Urban Areas. In Proceedings of the 16th Swiss Transport Research Conference, Monte Verità/Ascona, Switzerland, 18-20 May 2016; p. 11.

46. Tientrakool, P.; Ho, Y.-C.; Maxemchuk, N.F. Highway Capacity Benefits from Using Vehicle-to-Vehicle Communication and Sensors for Collision Avoidance. In Proceedings of the 2011 IEEE Vehicular Technology Conference (VTC Fall), San Francisco, CA, USA, 5-8 September 2011; pp. 1-5.

47. Shladover, S.E.; Su, D.; Lu, X.-Y. Impacts of Cooperative Adaptive Cruise Control on Freeway Traffic Flow. Transp. Res. Rec. 2012, 2324, 63-70. [CrossRef]

48. Hörl, S.; Ruch, C.; Becker, F.; Frazzoli, E.; Axhausen, K.W. Fleet Operational Policies for Automated Mobility: A Simulation Assessment for Zurich. Transp. Res. 2019, 102, 20-31. [CrossRef]

49. Nourinejad, M.; Bahrami, S.; Roorda, M.J. Designing Parking Facilities for Autonomous Vehicles. Transp. Res. 2018, 109, 110-127. [CrossRef]

50. Zhang, W.; Guhathakurta, S.; Fang, J.; Zhang, G. Exploring the Impact of Shared Autonomous Vehicles on Urban Parking Demand: An Agent-Based Simulation Approach. Sustain. Cities Soc. 2015, 19, 34-45. [CrossRef]

51. Zakharenko, R. Self-Driving Cars Will Change Cities. Reg. Sci. Urban Econ. 2016, 61, 26-37. [CrossRef]

52. Gelauff, G.; Ossokina, I.; Teulings, C. Spatial Effects of Automated Driving: Dispersion, Concentration or Both? KiM Netherlands Institute for Transport Policy Analysis: Haag, The Netherlands, 2017.

53. Faisal, A.; Yigitcanlar, T.; Kamruzzaman, M.; Currie, G. Understanding Autonomous Vehicles: A Systematic Literature Review on Capability, Impact, Planning and Policy. J. Transp. Land Use 2019, 12, 45-73. [CrossRef]

54. Nguyen, T.; Xie, M.; Liu, X.; Arunachalam, N.; Rau, A.; Lechner, B.; Busch, F.; Wong, Y.D. Platooning of Autonomous Public Transport Vehicles: The Influence of Ride Comfort on Travel Delay. Sustainability 2019, 11, 5237. [CrossRef]

55. Patella, S.M.; Scrucca, F.; Asdrubali, F.; Carrese, S. Carbon Footprint of Autonomous Vehicles at the Urban Mobility System Level: A Traffic Simulation-Based Approach. Transp. Res. 2019, 74, 189-200. [CrossRef]

56. Hörl, S.; Balac, M.; Axhausen, K.W. Dynamic Demand Estimation for an AMoD System in Paris. In Proceedings of the 2019 IEEE Intelligent Vehicles Symposium (IV), Paris, France, 9-12 June 2019; pp. 260-266. 
57. Martinez, L.M.; Viegas, J.M. Assessing the Impacts of Deploying a Shared Self-Driving Urban Mobility System: An Agent-Based Model Applied to the City of Lisbon, Portugal. Int. J. Transp. Sci. Technol. 2017, 6, 13-27. [CrossRef]

58. Bösch, P.M.; Ciari, F.; Axhausen, K.W. Transport Policy Optimization with Autonomous Vehicles. Transp. Res. Rec. 2018, 2672, 698-707. [CrossRef]

59. Oh, S.; Lentzakis, A.F.; Seshadri, R.; Ben-Akiva, M. Network Impacts of Automated Mobility-on-Demand: A Macroscopic Fundamental Diagram Perspective. arXiv 2020, arXiv:2011.05092.

60. Luo, L.; Parady, G.T.; Takami, K.; Harata, N. Evaluating the Impact of Autonomous Vehicles on Accessibility Using Agent-Based Simulation-A Case Study of Gunma Prefecture. J. JSCE 2019, 7, 100-111. [CrossRef]

61. Rasouli, A.; Tsotsos, J.K. Autonomous Vehicles That Interact with Pedestrians: A Survey of Theory and Practice. arXiv 2018, arXiv:1805.11773. [CrossRef]

62. Booth, L.; Norman, R.; Pettigrew, S. The Potential Implications of Autonomous Vehicles for Active Transport. J. Transp. Health 2019, 15, 100623. [CrossRef]

63. Alessandrini, A.; Campagna, A.; Site, P.D.; Filippi, F.; Persia, L. Automated Vehicles and the Rethinking of Mobility and Cities. Transp. Res. Procedia 2015, 5, 145-160. [CrossRef]

64. Fernandes, P.L.; Nunes, U. Multiplatooning Leaders Positioning and Cooperative Behavior Algorithms of Communicant Automated Vehicles for High Traffic Capacity. IEEE Trans. Intell. Transp. Syst. 2015, 16, 1172-1187. [CrossRef]

65. Millard-Ball, A. Pedestrians, Autonomous Vehicles, and Cities. J. Plan. Educ. Res. 2016, 38, 6-12. [CrossRef]

66. Bösch, P.M.; Becker, F.; Becker, H.; Axhausen, K.W. Cost-Based Analysis of Autonomous Mobility Services. Transp. Policy 2018, 64, 76-91. [CrossRef]

67. Sinner, M.; Brawand, S.; Weidmann, U. Networking Planning with Autonomous Buses. In Proceedings of the Transportation Research Board 97th Annual Meeting, Washington, DC, USA, 7-11 January 2018.

68. Hörl, S.; Becker, F.; Axhausen, K.W. Simulation of Price, Customer Behaviour and System Impact for a Cost-Covering Automated Taxi System in Zurich. Transp. Res. 2021, 123, 102974. [CrossRef]

69. Becker, H.; Becker, F.; Abe, R.; Bekhor, S.; Belgiawan, P.F.; Compostella, J.; Frazzoli, E.; Fulton, L.M.; Guggisberg Bicudo, D.; Murthy Gurumurthy, K.; et al. Impact of Vehicle Automation and Electric Propulsion on Production Costs for Mobility Services Worldwide. Transp. Res. 2020, 138, 105-126. [CrossRef]

70. Jing, P.; Xu, G.; Chen, Y.; Shi, Y.; Zhan, F. The Determinants behind the Acceptance of Autonomous Vehicles: A Systematic Review. Sustainability 2020, 12, 1719. [CrossRef]

71. Brownell, C.; Kornhauser, A. A Driverless Alternative. Transp. Res. Rec. 2014, 2416, 73-81. [CrossRef]

72. Harper, C.D.; Hendrickson, C.T.; Mangones, S.; Samaras, C. Estimating Potential Increases in Travel with Autonomous Vehicles for the Non-Driving, Elderly and People with Travel-Restrictive Medical Conditions. Transp. Res. 2016, 72, 1-9. [CrossRef] 